\title{
Relations between histopathology and parasitaemias in Oncorhynchus mykiss infected with Cryptobia salmositica, a pathogenic haemoflagellate
}

\author{
M. Bahmanrokh, Patrick T. K. Woo* \\ Department of Zoology, University of Guelph, Guelph, Ontario N1G 2W1, Canada
}

\begin{abstract}
One group $(\mathrm{n}=50)$ of juvenile rainbow trout Oncorhynchus mykiss was inoculated intraperitoneally with 2000 (low dose [LD]) and another group $(\mathrm{n}=50)$ with 20000 (high dose [HD]) Cryptobia salmositica fish ${ }^{-1}$. The histopathology was a generalised inflammatory reaction, and lesions were in connective tissues and in the reticulo-endothelial system. In the LD group, the first lesions were observed in the liver, gills and spleen at $2 \mathrm{wk}$ post infection (pi) while in the HD group they were in the liver and gills at $1 \mathrm{wk}$ pi. Endovasculitis and mononuclear cell infiltration were observed at $3 \mathrm{wk}$ pi in the HD group. These were followed by tissue necrosis and extravascular infiltration of parasites at $4 \mathrm{wk}$ pi. The severity of lesions was directly related to parasitaemias in the blood and extravascular location of parasites. In the HD group, the most extensive tissue necrosis was at $4 \mathrm{wk}$ pi and in the LD group it was 6 to $7 \mathrm{wk}$ pi. Necrosis in the vital organs (liver, kidney and depletion of the haematopoeitic tissues) and anaemia were probably in part responsible for mortality of fish during acute disease. Regeneration and replacement of necrotic tissues were seen at 7 to $9 \mathrm{wk}$ pi in the HD group, and it was most noticeable in haematopoietic and reticular tissues. These occurred during the recovery phase of the disease and were associated with significant reduction in blood parasitaemia.
\end{abstract}

KEY WORDS: Cryptobia salmositica $\cdot$ Oncorhynchus mykiss $\cdot$ Histopathology Parasitaemias

\section{INTRODUCTION}

Cryptobia salmositica Katz is a pathogenic haemoflagellate in Oncorhynchus spp. in rivers and streams on the Pacific coast of North America (Woo 1998). The parasite multiplies readily in susceptible fish, and mortality is variable and may be up to $100 \%$ in untreated fish (Woo \& Poynton 1995, Ardelli \& Woo 2001). Factors that may affect fish mortality include size on inoculum, water temperature, dissolved oxygen in the water, amount of protein in the food and fish stocks or species (e.g., Woo 1979, Woo et al. 1983, Woo \& Wehnert 1986, Li \& Woo 1991, Ardelli \& Woo 2001). As in mammalian trypanosomiasis, C. salmositica infection causes

${ }^{*}$ Corresponding author. E-mail: pwoo@uoguelph.ca immunodepression (Jones et al. 1986, Thomas \& Woo 1992), an anaemia that is partly caused by excretory products from the parasite (Thomas \& Woo 1988, 1989, Zuo \& Woo 1998a,b, 2000). The severity of the anaemia is directly related to the parasitaemia (Woo 1979) as is the anorexia (Li \& Woo 1991, Thomas \& Woo 1992).

The clinical signs of salmonid cryptobiosis are anorexia, exophthalmia, abdominal distension with ascites, general oedema, splenomegaly and a microcytic hypochromic anaemia (Woo 1979). However, the histopathology of the disease has not been systematically studied in infected fish.

The aim of the present study was to describe systematically the development of lesions or changes in experimentally infected juvenile rainbow trout and to relate it to the parasitaemias. 


\section{MATERIALS AND METHODS}

Two groups ( $\mathrm{n}=50$ in each group) of hatchery-raised juvenile rainbow trout (about 6 to $8 \mathrm{~cm}$ in length) were maintained in 2 fibre glass tanks at about $8^{\circ} \mathrm{C}$ for $2 \mathrm{wk}$ before they were experimentally infected with Cryptobia salmositica. The inocula were prepared with blood from an infected rainbow trout and diluted with appropriate volumes of PBS ( $\mathrm{pH}$ 7.4). The low dose (LD) group was inoculated intraperitoneally (ip) with 2000 parasites fish ${ }^{-1}$ and the high dose (HD) group with 20000 parasites fish ${ }^{-1}$.

At weekly intervals, 4 fish from each group were anesthetised with MS-222 (100 ppm), bled and necropsied. In the first week after infection the parasitaemias in the blood were detected using the haematocrit centrifuge technique (Woo \& Wehnert 1983) and wet mount method (24 microscopic fields examined, 10× objective). In subsequent weeks, the haemocytometer was used to estimate parasitaemias (Woo 1979). For histopathology, samples of visceral organs, skin, eye, brain and gills were fixed in $10 \%$ formalin, embedded in paraffin, sectioned into $4 \mu \mathrm{m}$ thick pieces, and stained with haematoxylin and eosin. Smears of ascites fluid or blood were air dried, fixed in 100\% Ethanol and stained with Giemsa's stain. A third group of uninfected fish (controls) was also sampled.

\section{RESULTS}

\section{LD group}

The haematocrit centrifuge technique detected parasites in the blood of all fish at $1 \mathrm{wk}$ post infection (pi).
The parasitaemia increased rapidly, peaked at $6 \mathrm{wk}$ pi, and declined to low numbers at 8 to 9 wk pi (Fig. 1) Data on parasitaemias in the fish were published earlier (Sitja-Bobadilla \& Woo 1994) and the figure is reproduced in the current study so as to relate the types and severity of histopatholigical lesions with parasitaemias in the blood.

The first lesions were in the liver, spleen and gills at 2 wk pi. Chromatin of the nuclei of hepatocytes was disarranged from the normal wheel-network to being granular. Also, the endothelial cells lining the sinusoids seemed hypertrophic and swollen with small foci of cell necrosis. The spleen had multifocal hyperplastic reticular cells. Eosinophilic granular cells (EGCs) were seen within blood vessels and interlamellar space in the gills.

At 3 wk pi, almost all organs examined had mild mononuclear cell infiltration and diapedesis. The liver had granular degeneration with focal necrosis. Epithelial cells lining renal tubules in the kidneys were vacuolated or granular and there was mild lymphocyte infiltration. In the gills, there was focal epithelial cell necrosis with endovasculitis in the secondary lamellae. The infiltrated cells in the gills were polymorphonuclear cells, macrophages and EGCs. Lesions in the gut and abdominal adipose and subcutaneous tissues were minor and were confined to connective tissues. There were mononuclear cell infiltrations, dilated blood vessels and diapedesis.

At $4 \mathrm{wk}$ pi, necrosis and extravascular parasites were in all organs examined. The serous layer of visceral organs, gut and gall bladder had mild inflammatory cell reactions associated with focal necrosis and endoperivasculitis. The connective tissues of the eyes, skin, subcutaneous tissues, pericardium and swim

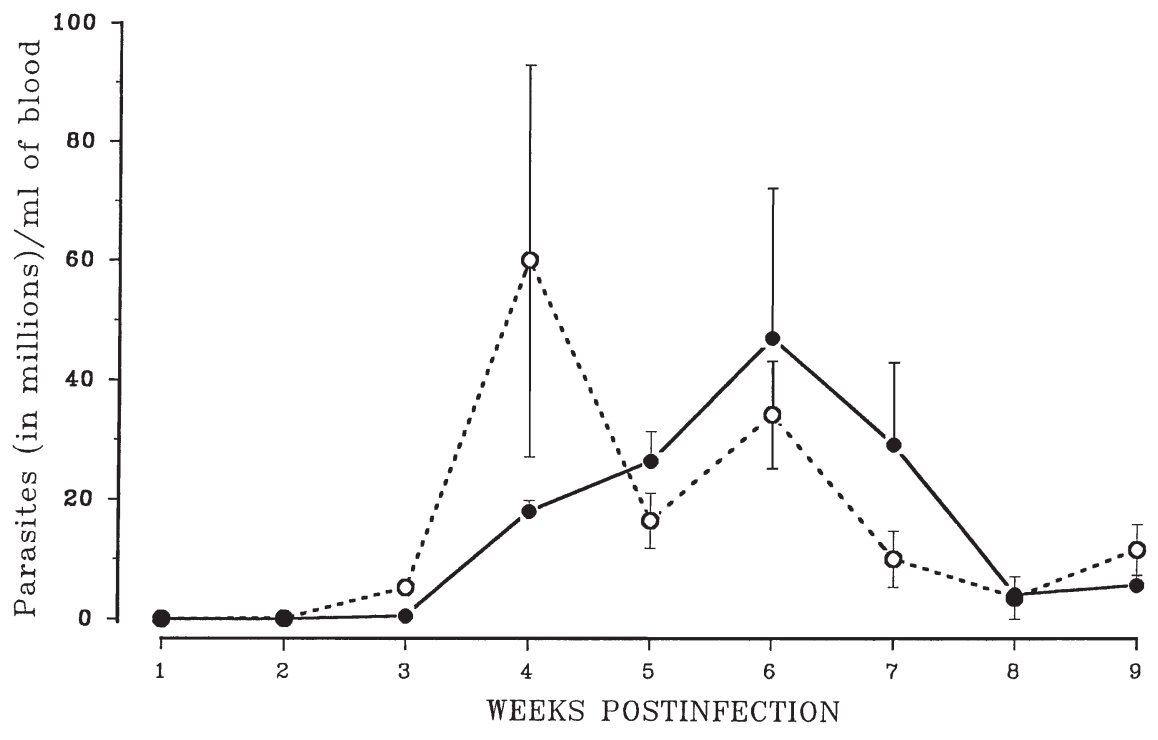

Fig. 1. Parasitaemias in juvenile Oncorhynchus mykiss experimentally infected with low dose (2000 Cryptobia salmositica fish ${ }^{-1}$ : ๑) and high dose $(20000$ C. salmositica fish $^{-1}$ : o) of parasite. Reproduced with permission of $J$ Fish Dis from Sitja-Bobadilla \& Woo (1994) 
bladder had perivasculitis, lymphocytic cell cuffs and extravascular parasites. Spongiosis and local sloughoff in the cornea and epidermis were evident. In the liver, there were diffused hepatocyte degeneration and focal necrosis. The anterior kidney had lost its lobular structure and the reno-haematopoietic tissues were necrotic. In the spleen, the extensive reticular hyperplasia became necrotic and this was associated with inflammatory cells and extravascular parasite infiltration. The posterior kidney showed diffused tubular degeneration. The renal tubules became disarranged and eventually disappeared in areas of necrosis. Proliferative glomerulonephritis was also evident. At $5 \mathrm{wk}$ $\mathrm{pi}$, there were more phagocytes, parasites and cell debris in most tissue sections especially in those from the liver, kidneys and spleen.

The most severe and destructive lesions were seen at 6 and 7 wk pi (peak parasitaemias in the blood; Fig. 1). There was extensive necrosis with numerous parasites in the connective tissues of the abdominal wall, eyes and skin. The inflammation extended from the serosa to the smooth muscles of the gut, gallbladder, swim bladder and myocardium. Healthy tissues in the spleen and kidneys were replaced with necrotic exudates. The gills were necrotic and there was hypertrophy of epithelial cells in the secondary lamellae. The gill lamellae were oedematous with cell infiltration and were thickened. Their blood vessels were dilated and filled with parasites, and there were many EGCs and free granules. Lesions were also evident at this time. They consisted of gliosis, local inflammation and capillaries occluded with parasites. At 7 wk pi, early regeneration was seen in renal haematopoietic tissues, and the tissues regained their normal lobular structure by 8 and 9 wk pi. The parasitaemia was low (Fig. 1) at this time and the spleen had massive numbers of disintegrated erythrocytes, extensive necrosis and extravascular parasites. Extensive lesions were also present in connective tissues in the gut, skin, gallbladder, eye and adipose tissues at $9 \mathrm{wk}$ pi.

\section{HD group}

Parasites were detected at $1 \mathrm{wk} \mathrm{pi}$, and parasitaemia peaked at $4 \mathrm{wk}$ pi and declined to low numbers at 7 and 8 wk pi (Fig. 1). Lesions in tissues and organs were similar to but more severe than those described in the LD group. First lesions were in the liver and gills at $1 \mathrm{wk}$ pi. Tissue necrosis was in most organs at $3 \mathrm{wk}$ pi and most severe lesions were at $4 \mathrm{wk}$ pi. The number of inflammatory cells, parasitaemia and necrosis were reduced by 6 and 7 wk pi. The kidney had newly regenerated tubules by the 7 th week, and this was more pronounced and almost completed by 8 to $9 \mathrm{wk}$ pi. Similarly, haematopoietic tissues in the kidney and spleen proliferated and were near normal at this time. The spleen had large numbers of erythrocytes while the liver had cells with mitotic figures and regenerated cells at 9 wk pi. The hepatic sinusoids were dilated, and still had a few small foci of necrosis but no extravascular parasites. In the kidney, peritubular fibrosis was seen in 1 fish at $7 \mathrm{wk}$ pi. There were cellular debris and parasites within some macrophages. In contrast, there were extensive lesions in the eyes and heart at 9 wk pi. Numerous parasites were within capillaries in connective tissues in the ulcerated cornea. Parasites were occluding capillaries and these lesions resembled thrombosis. Also, connective tissues of the heart showed diffuse inflammation. Gill lesions included necrosis and fusion of lamellae at $9 \mathrm{wk}$ pi but there were no EGCs and extravascular parasites.

\section{DISCUSSION}

Little is known about the histopathology and its relations to parasitaemias in fish infected with Cryptobia salmositica, although much is known about the mechanism of disease and control strategies against cryptobiosis (Woo 1998). Putz (1972) showed that the parasite occludes capillaries and there are oedematous areas behind the eye, subcutaneous tissues, kidneys, gills and skin in coho salmon infected with C. salmositica. Many lesions seen in the present study in infected rainbow trout were similar to those in cyprinids infected with Trypanosoma danilewskyi and Trypanoplasma borreli, in that there are tubular necrosis, extravascular parasites, liver degeneration and focal necrosis, phagocytosis of parasites, disintegrated erythrocytes in the spleen, swollen endothelial cells and changes in adipose tissues (Dykova \& Lom 1979, Bunnajirakul et al. 2000, Rudat et al. 2000).

Lesions in the gills of Cryptobia salmositica-infected trout (present study) were similar to those in chinook salmon with systemic hexamitid infection, and they include epithelial cell oedema and dilated blood vessels with mixed inflammatory cells (granulocytes, macrophages and lymphocytes) in the primary lamellae. Lesions in the gut and heart (present study) were also similar to those in hexamitosis (Kent et al. 1992). Catfish with systemic amoebiosis also had proliferative lesions in the gills and vascular damage and thrombosis (Nash et al. 1988). Hyperplasia and eosinophilic cells in the gills were also seen in sea bass infected with monogeneans (Gonzalez-Lanza et al. 1991).

Anaemia in goldfish infected with Trypanosoma danilewskyi is partly caused by haemolysis and haemodilution (Islam \& Woo 1991), similar to that in salmonid cryptobiosis (Thomas \& Woo 1988). There 
were also lesions and changes in the haematopoietic tissues in cryptobiosis in rainbow trout (present study). During acute cryptobiosis haematopoietic lobules were depleted in the kidney and spleen, and these were replaced with necrotic and inflammatory cells. This reduction of haematopoietic structures would also contribute to the anaemia. Extravascular parasite infiltration (associated with tissue necrosis) seemingly overwhelmed the inflammatory response, and this is a very distinctive pathological pattern in salmonid cryptobiosis.

Cysteine and metalloproteases from Cryptobia salmositica have been isolated, purified and characterised (Zuo \& Woo 1997a,b). The cysteine protease is a metabolic enzyme while the metalloprotease is an important contributing factor to the anaemia in salmonid cryptobiosis (Zuo \& Woo 1998a). The purified metalloprotease lyses fish erythrocytes under in vitro conditions (Zuo \& Woo 2000) by digesting the erythrocyte membrane proteins (Zuo \& Woo 1997b). This is the haemolysin that was identified earlier as 1 of the causes of anaemia in C. salmositica-infected fish (Thomas \& Woo 1988, 1989). The metalloprotease is also collagenolytic as it degrades various collagens (types I, IV and V) and laminin (Zuo \& Woo 1997b). Since its in vitro secretion by the $C$. salmositica is significantly increased in the presence of either type I or type IV collagen (Zuo \& Woo 1998b), this histolytic enzyme is a major virulent factor. Secretion of the metalloprotease by the pathogen would allow some parasites to leave the vascular system for extravascular space, and would explain the severe histopathology during high parasitaemias and regeneration of tissues during chronic cryptobiosis when parasitaemias were low (present study).

EGCs in blood vessels and connective tissues with 'free' granules in gills were coincident with extravascular location of parasites and tissue necrosis. EGCs have been reported in connective tissues of the intestine and gills in salmonids, but their function is not well understood (Bergeron \& Woodward 1982). These cells may be histaminogenic (Ellis 1982, 1985). There was evidence of degranulation of EGCs with free granules in the gut and histamine in the blood $1 \mathrm{~h}$ after injection of extracellular products of Aeromonas salmonicida (Ellis 1985). Extracellular products of the bacterium have proteolytic and toxic activity in rainbow trout, and Munro et al. (1980) suggested that its protease and phospholipase activity act directly on the EGCs.

Lesions caused by Cryptobia salmositica penetrating blood vessels, and hypertrophy and necrosis of endothelial cells lead to vasculitis and thrombosis in tissues (present study). These are similar to the vascular damage in systemic amoebiasis in catfish (Nash et al. 1988). The presence of lysed C. salmositica in or beside macrophages, the appearance of plasma-like cells, decreased numbers of parasites and the regeneration of damaged tissues occurred during the recovery phase of the disease, indicating an active humoral and cellular response. Li \& Woo (1995) observed complement fixing antibodies in the blood of fish at $6 \mathrm{wk}$ pi and 2 wk after parasite challenge in vaccinated fish. They also showed enhanced phagocytosis and cell mediated cytotoxicity in vaccinated and challenged rainbow trout. This and other studies (e.g., Woo 1979, Jones \& Woo 1987, Thomas \& Woo 1990, Ardelli \& Woo 1995, Li \& Woo 1995, 1997, Feng \& Woo 1996, 1997) confirm that both humoral and cell mediated immunity are important in protection, and that intravascular and extravascular lysis of parasites occur in cryptobiosis.

Acknowledgements. This study was supported by a grant from the Natural Sciences and Engineering Research Council (Canada) to P.T.K.W. Dr M. Bahmanrokh was on study leave from the Tehran University of Medical Sciences, and the Ministry of Education and Medical Education, Iran. Fig. 1 is reproduced with permission from the Journal of Fish Diseases.

\section{LITERATURE CITED}

Ardelli BF, Woo PTK (1995) Immune response of Cryptobiaresistant and Cryptobia-susceptible Salvelinus fontinalis to an Aeromonas salmonicida vaccine. Dis Aquat Org 23: 33-38

Ardelli BF, Woo PTK (2001) Therapeutic and prophylactic effects of isometamidium chloride (Samorin) against the haemoflagellate Cryptobia salmositica in chinook salmon (Oncorhynchus tshawytscha). Parasitol Res 87:18-26

Bergeron T, Woodward B (1982) The development of the stratum granulosum of the small intestine of rainbow trout (Salmo gairdneri). Can J Zool 60:1513-1516

Bunnajirakul S, Steinhagen D, Hetzel U, Korting W, Drommer W (2000) A study of sequential histopathology of Trypanoplasma borreli (Protozoa: Kinetoplastida) in susceptible common carp Cyprinus carpio. Dis Aquat Org 39: 221-229

Dykova I, Lom J (1979) Histopathological changes in Trypanosoma danilewskyi Laveran \& Mesnil, 1904 and Trypanoplasma borreli Laveran \& Mesnil, 1902 infections of goldfish, Carassius auratus (L.). J Fish Dis 2:381-390

Ellis AE (1982) Histamine, mast cells and hypersensitivity responses in fish. Dev Comp Immunol Suppl 2:147-155

Ellis AE (1985) Eosinophilic granular cells (EGC) and histamine responses to Aeromonas salmonicida toxins in rainbow trout. Dev Comp Immunol 9:251-260

Feng S, Woo PTK (1996) Cell-mediated immune response and T-like cells in thymectomized Oncorhynchus mykiss (Walbaum) infected with or vaccinated against the pathogenic hemoflagellate Cryptobia salmositica Katz 1951. Parasitol Res 82:604-611

Feng S, Woo PTK (1997) The therapeutic and prophylactic effects of a protective monoclonal antibody (MAb-001) against the pathogenic haemoflagellate Cryptobia salmositica Katz 1951. Dis Aquat Org 28:211-219

Gonzalez-Lanza C, Alvarez-Pellitero P, Sitja-Bobadilla A (1991) Diplectanidae (Monogenea) infestations of sea bass, Dicentrarchus labrax (L.), from the Spanish Mediter- 
ranean area, histopathology and population dynamics under culture conditions. Parasitol Res 77:307-314

Islam AKMN, Woo PTK (1991) Anemia and its mechanism in goldfish, Carassius auratus infected with Trypanosoma danilewskyi. Dis Aquat Org 11:37-43

Jones SRM, Woo PTK (1987) The immune response of rainbow trout, Salmo gairdneri Richardson to the haemoflagellate, Cryptobia salmositica Katz 1951. J Fish Dis 10: 395-402

Jones SRM, Woo PTK, Stevenson RMW (1986) Immunosuppression in Salmo gairdneri caused by the haemoflagellate, Cryptobia salmositica. J Fish Dis 9:931-938

Kent ML, Ellis J, Fournie JW, Dawe SC, Bagshaw JW, Whitaker DJ (1992) Systemic hexamitid (Protozoa: Diplomonadida) infection in seawater pen-reared chinook salmon, Oncorhynchus tshawytscha. Dis Aquat Org 14: 81-89

Li S, Woo PTK (1991) Anorexia reduces the severity of cryptobiosis in Oncorhynchus mykiss. J Parasitol 77:467-471

Li S, Woo PTK (1995) Efficacy of a live Cryptobia salmositica vaccine, and the mechanism of protection in vaccinated Oncorhynchus mykiss (Walbaum) against cryptobiosis. Vet Immunol Immunopathol 48:343-353

Li S, Woo PTK (1997) Vaccination of rainbow trout, Oncorhynchus mykiss (Walbaum) against cryptobiosis: efficacy of the vaccine in fresh and sea water. J Fish Dis 20:369-374

Munro ALS, Hastings TS, Ellis AE, Liversidge J (1980) Studies on ichthyotoxic material produced extra cellularly by the furunculosis bacterium Aeromonas salmonicida. In: Ahne W (ed) Fish diseases. Springer-Verlag, Berlin, p 98-106

Nash G, Nash M, Schlotfeldt HJ (1988) Systemic amoebiasis in cultured European catfish, Silurus glanis J. J Fish Dis 11:57-71

Putz RE (1972) Biological studies on the hemoflagellates Cryptobia cataractae and Cryptobia salmositica. Tech Pap US Fish Wildl Serv 18-22

Rudat S, Steinhagen D, Hetzel U, Drommer W, Korting W (2000) Cytopathological observations on renal tubule epithelium cells in common carp Cyprinus carpio under Trypanoplasma borreli (Protozoa: Kinetoplastida) infection. Dis Aquat Org 40:203-209

Sitja-Bobadilla A., Woo PTK (1994) An enzyme-linked immunosorbent assay (ELISA) for the detection of antibodies against the pathogenic haemoflagellate, Cryptobia salmositica Katz and protection against cryptobiosis in juvenile Oncorhynchus mykiss (Walbaum) inoculated with a live Cryptobia vaccine. J Fish Dis 17:399-408

Thomas PT, Woo PTK (1988) Cryptobia salmositica: in vitro and in vivo study on the mechanism of anaemia in infected rainbow trout, Salmo gairdneri. J Fish Dis 11:425-431

Editorial responsibility: Wolfgang Körting,

Hannover, Germany
Thomas PT, Woo PTK (1989) An in vitro study on the haemolytic components of Cryptobia salmositica. J Fish Dis 12:389-393

Thomas PT, Woo PTK (1990) In vivo and in vitro cell-mediated immune responses of Oncorhynchus mykiss against Cryptobia salmositica (Sarcomastigophora: Kinetoplastida). J Fish Dis 13:423-433

Thomas PT, Woo PTK (1992) Anorexia in Oncorhynchus mykiss infected with Cryptobia salmositica (Sarcomastigophora: Kinetoplastida): its onset and contribution to the immunodepression. J Fish Dis 15:443-447

Woo PTK (1979) Trypanoplasma salmositica: experimental infections in rainbow trout, Salmo gairdneri. Exp Parasitol 47:36-48

Woo PTK (1998) Protection against Cryptobia (Trypanoplasma) salmositica and salmonid cryptobiosis. Parasitol Today 14:272-277

Woo PTK, Poynton S (1995) Diplomonadida, Kinetoplastida and Amoebida. In: Woo PTK (ed) Fish diseases and disorders, Vol 1. Protozoan and metazoan infections. $\mathrm{CAB}$ International, Oxon, p 27-96

Woo PTK, Wehnert SD (1983) Direct transmission of a haemoflagellate, Cryptobia salmositica Katz 1951 (Kinetoplastida: Bodonina) between rainbow trout under laboratory conditions. J Protozool 39:334-337

Woo PTK, Wehnert SD (1986) Cryptobia salmositica: susceptibility of infected trout, Salmo gairdneri, to environmental hypoxia. J Parasitol 72:392-396

Woo PTK, Wehnert SD, Rodger D (1983) The susceptibility of fishes to hemoflagellates at different ambient temperatures. Parasitology 87:385-392

Zuo X, Woo PTK (1997a) Proteases in pathogenic and nonpathogenic hemoflagellates, Cryptobia spp. (Sarcomastigophora: Kinetoplastida) of fishes. Dis Aquat Org 29: $57-65$

Zuo X, Woo PTK (1997b) Purified metallo-protease from the pathogenic haemoflagellate, Cryptobia salmositica, and its in vitro proteolytic activities. Dis Aquat Org 30: $177-185$

Zuo X, Woo PTK (1998a). Characterization of purified metallo- and cysteine proteases from the pathogenic haemoflagellate, Cryptobia salmositica Katz 1951. Parasitol Res 84:492-498

Zuo X, Woo PTK (1998b) In vitro secretion of metallo-protease $(200 \mathrm{kDa})$ by the pathogenic piscine haemoflagellate, Cryptobia salmositica Katz, and stimulation of protease production by collagen. J Fish Dis 21:249-255

Zuo X, Woo PTK (2000) In vitro haemolysis of piscine erythrocytes by purified metalloprotease from the pathogenic haemoflagellate, Cryptobia salmositica Katz. J Fish Dis 23: $227-230$

Submitted: March 5, 2001; Accepted: June 16, 2001

Proofs received from author(s): August 8, 2001 